\title{
Research on In Situ Stress Distribution of the Railway Tunnels in Southwest China Based on the Complete Temperature Compensation Technology
}

\author{
Weibin Ma $\mathbb{D}^{1,2}$, Jinfei Chai ${ }^{1},{ }^{1,2}$ Degou Cai $\mathbb{D}^{1,2}$ Xiaoyan Du ${ }^{1},{ }^{1,2}$ Jie Dong, ${ }^{3}$ Siming Tian, ${ }^{4}$ \\ Peng Zhao, ${ }^{1,2}$ Ziyuan Liu, ${ }^{1,2}$ and Wei $\mathrm{Cui}^{5}$ \\ ${ }^{1}$ Railway Engineering Research Institute, China Academy of Railway Sciences Corporation Limited, Beijing 100081, China \\ ${ }^{2}$ State Key Laboratory for Track Technology of High-Speed Railway, Beijing 100081, China \\ ${ }^{3}$ Hebei Institute of Architecture Civil Engineering, Zhangjiakou 075000, Hebei, China \\ ${ }^{4}$ China Railway Economic and Planning Research Institute, Beijing 100038, China \\ ${ }^{5}$ Zhengzhou Branch, China Railway Container Transportation Corporation Limited, Zhengzhou 450015, Henan, China
}

Correspondence should be addressed to Jinfei Chai; chaijinfei@rails.cn, Degou Cai; caidegou@126.com, and Xiaoyan Du; 466074024@qq.com

Received 6 September 2021; Accepted 8 November 2021; Published 8 December 2021

Academic Editor: fan feng

Copyright (c) 2021 Weibin Ma et al. This is an open access article distributed under the Creative Commons Attribution License, which permits unrestricted use, distribution, and reproduction in any medium, provided the original work is properly cited.

\begin{abstract}
In situ stress is the natural stress existing in the stratum without engineering disturbance, also known as initial stress, absolute stress, or original rock stress. In order to master the in situ stress of the Manmushu Tunnel and Mamo Tunnel in Southwest China, the casing stress solution method is adopted in this paper. Through the combination of field measurement and laboratory test, the basic data such as initial strain during stress relief are collected, and the in situ stress values are analyzed in combination with indoor temperature compensation test, confining pressure calibration, and relevant rock mechanics tests. The measured results show the following: (1) the maximum horizontal principal stress $\sigma_{h \text { max }}$ ranges from $6.44 \mathrm{MPa}$ to $19.74 \mathrm{MPa}$; the vertical principal stress $\sigma_{v}$ ranges from 4.11 MPa to 13.48 MPa; and the minimum horizontal principal stress ranges from 4.32 $\mathrm{MPa}$ to $11.22 \mathrm{MPa}$. (2) The maximum horizontal principal stress directions of the five measuring points are all located in the NW direction, which is basically consistent with the maximum principal stress direction of the regional tectonic stress field. The maximum horizontal principal stress $\left(\sigma_{h \text { max }}\right)$, the minimum horizontal principal stress $\left(\sigma_{h \text { min }}\right)$, and the vertical principal stress $\left(\sigma_{v}\right)$ all increase with the increase of buried depth, and the relationship is approximately linear. It is suggested that, in the actual construction process, the construction method and construction parameters should be optimized scientifically and reasonably to reduce the disturbance of blasting on the tunnel surrounding rock. After tunnel excavation, support measures should be taken quickly, timely, and scientifically to reduce and control the deformation of the surrounding rock.
\end{abstract}

\section{Introduction}

In situ stress is the natural stress existing in the stratum and not disturbed by engineering, also known as initial stress, absolute stress, or original stress of rock mass. In situ stress is gradually formed in the long geological history, which is mainly the result of the combined action of gravity field and tectonic stress. It is an important design parameter of various ground, underground engineering, slope, tunnel, and other engineering. It is one of the most important factors affecting the safety and stability of geotechnical engineering.

The causes of in situ stress are very complex. The field measurement and theoretical analysis for more than 30 years show that the formation of in situ stress is mainly related to various dynamic processes of the Earth, including plate boundary compression, mantle thermal convection, Earth internal stress, gravity, Earth rotation, magma intrusion, and heterogeneous crustal expansion. In addition, uneven temperature, water pressure gradient, surface erosion, or 
other physical and chemical changes can also cause the corresponding stress field.

Once, some scholars were mainly concerned about how to use mathematical equations to quantitatively calculate the in situ stress and thought that the in situ stress was mainly vertical stress. However, further research shows that gravity and tectonic movement are the main causes of in situ stress, and the horizontal tectonic movement has the greatest influence on the formation of the in situ stress field. The current stress state is mainly controlled by the latest tectonic movement, but it is also related to the historical tectonic movement. For hundreds of millions of years, the Earth has experienced numerous tectonic movements, which have resulted in the complexity and variability of the in situ stress state. Therefore, the only way to understand the in situ stress state of an area is to carry out in situ stress measurement.

In situ stress measurement is to determine the state of a natural three-dimensional stress field existing around mining engineering. This kind of measurement is usually done by measuring point by point. The three-dimensional stress state of a point in the rock mass can be represented by six components $\left(\sigma_{x}, \sigma_{y}, \sigma_{z}, \tau_{x y}, \tau_{y z}\right.$, and $\left.\tau_{z x}\right)$ in the selected coordinate system, as shown in Figure 1. This kind of coordinate system can be selected according to the need and convenience. Generally, the Earth coordinate system is taken as the surveying coordinate system. The magnitude and direction of the three principal stresses can be obtained from the six stress components, and the solution is unique. In actual measurement, the rock involved in each measurement point may range from several cubic centimeters to several thousand cubic meters, depending on the measurement method. Whether it is a few cubic centimeters or several thousand cubic meters, it can still be regarded as a point for the whole rock mass. Although there are some methods to measure the average stress in a wide range of rocks, such as ultrasonic measurement and other geophysical methods, these methods are far less accurate than the "point" measurement method. In order to accurately measure the in situ stress of a mining area, a sufficient number of point measurements must be carried out. On this basis, with the help of numerical analysis and mathematical statistics, the regional stress field model is established, which provides the basis for geotechnical design and calculation.

In 1932, Lieurace carried out the first in situ stress measurement in the world in the Harvard Dam discharge tunnel project in the United States, and the stress relief method was used in the field measurement [1]. In the early 1970s in the United States, the hydraulic fracturing method was proposed by Haimson and Fairhurst [2-4]. This method originated from the oil development work and formed the current hydraulic fracturing method after continuous improvement, which is the most widely used measurement method in the world [5-7]. Since the 1960s, American scholars have carried out in situ stress measurement in many areas, systematically and deeply studied the crustal stress state, and drew the regional principal stress direction map of the American continent for the first time. Zoback et al. compiled the horizontal stress direction map in the United States and the crustal stress zoning map of the continental

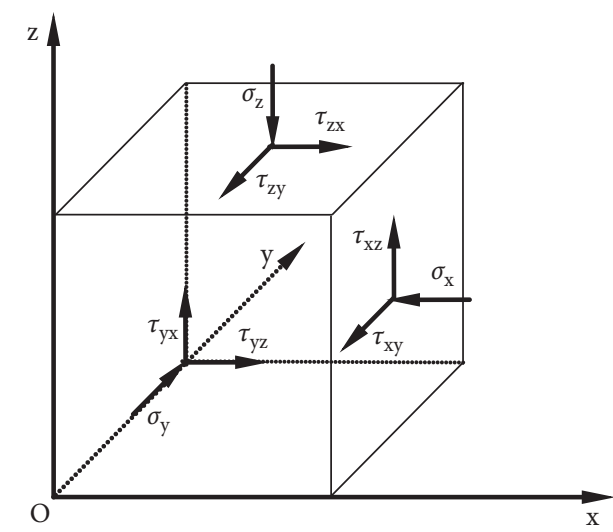

Figure 1: Stress state diagram of a point in rock mass.

United States in the 1980s [8, 9]. From 1986 to 1992, Zoback and more than 30 scholars from 18 countries jointly carried out the "World Stress Diagram Project" in order to reveal the direction and spatial distribution of tectonic stress in the global lithosphere. The project collected the measured data of different types of in situ stress in the world and carried out classification screening. On this basis, the first "World Stress Diagram" (WSM) was compiled, which better illustrated the dominant position of horizontal tectonic stress in the world [10-14]. In the late 1950s, the Mechanical Engineering Research Institute of the South African Council for Scientific and Industrial Research (CSIR) developed the aperture profiler. In the mid-1960s, Leeman studied the stress field around the hole under the action of an infinite three-dimensional stress field (including the cylindrical hole) based on elastic mechanics, which promoted the development of in situ stress measurement technology [15]. A third technique was developed independently both by Rocha et al. [16] and Worotnicki and Walton [17] to overcome the problem of the failure of the epoxy/rock bond [18]. As early as 1930s, Japan carried out in situ stress measurement for the needs of mining and underground engineering. At first, the stress recovery method was used, which has the advantages of simple operation and economic benefits [19]. In Portugal, the work of in situ stress measurement was carried out earlier. Rocha and the Institute of Civil Engineering jointly studied it. Firstly, some improvements were made to the flat jack, then the solid hollow inclusion strain gauge was developed, and soon, the hollow inclusion strain gauge was developed [20]. In addition, many countries have carried out stress measurement work.

The experiment and research of in situ stress measurement in China began in the 1960s. Li and Chen, as the main founders, first obtained the measured results of rock surface stress at the Pingshan dam site of the Three Gorges Project from 1962 to 1964. In 1964, under the leadership of Professor Chen, Wuhan Institute of Geomechanics, Chinese Academy of Sciences, conducted the first stress relief measurement in China at Daye Iron Mine, Hubei Province. The measurement depth was $-80 \mathrm{~m}$. At that time, the method was to stick a strain gauge on the rock surface and then open a circular groove around the strain gauge to realize stress relief. 
Therefore, the surface stress of rock mass is still measured by this method, not the original rock stress [21].

In 1966, under the initiative of $\mathrm{Li}$, the first in situ stress observation station in China was established in Shangyou County, Hebei Province. Since then, dozens of in situ stress observation stations have been established in 21 provinces, cities, and autonomous regions [22].

In the 1970s, many departments in China carried out a large number of in situ stress measurements in different areas, most of which were completed in the fields of earthquake, hydropower, and mining, making unprecedented progress in the field measurement [23].

The Institute of Crustal Stress has successfully carried out the first hydraulic fracturing stress measurement in Yixian County, Hebei Province, and China has since entered the field of deep in situ stress measurement [22]. Li and Wang measured and studied the stress relief method in North China and discussed the relationship between in situ stress and earthquake [24].

Yin used the acoustic emission method to measure in situ stress at the Xiaolangdi Dam of the Yellow River, which has the advantages of simple operation and low cost [25].

Cai analyzed and studied the temperature compensation [26] and the relationship between the state of in situ stress and the properties of the surrounding rock and studied the distribution characteristics and laws of in situ stress in the mining area by using the finite element method $[27,28]$.

The in situ stress measurement carried out by the Institute of Geomechanics of the Chinese Academy of Geological Sciences for the purpose of earthquake research covers nearly 100 measuring points all over the country. According to the measurement results, the variation of in situ stress with depth was studied [29]. Professor Ma compiled a map of modern tectonic stress field in China and its adjacent areas based on the measured data, focal mechanism solutions, and various geological information [30].

In the 21st century, in situ stress has developed in more fields, and many large-scale projects have applied in situ stress, such as Qinghai-Tibet railway, earthquake disaster research, and large-scale mine research. Larson et al. used GPS to analyze the dynamics of the collision process between India and Eurasia plates [31]. Fan et al., based on the Chinese Mainland block model, simulated and analyzed the distribution characteristics and controlling factors of plate tectonic and gravity current in situ stress field in the Chinese Mainland by using the linear viscoelastic shell finite element method [32]. In addition, many scholars and experts have analyzed and studied the characteristics and influencing factors of China's in situ stress field in different regions [33-47].

\section{Implementation Process of the In Situ Stress Measurement in the Manmushu Tunnel and Manmo Tunnel}

\subsection{Arrangement of In Situ Stress Measuring Points.} Based on the engineering geological survey and combined with the site construction conditions, the location of the measuring point is selected. The measuring point basically avoids the fault, rock fracture zone, and fault development zone, and the measuring point is far away from the large chamber as far as possible. In addition, the depth of the measured borehole is more than 2.5 times of the tunnel span, and the distance between the measured points and the adjacent tunnels or other excavation projects is more than $50 \mathrm{~m}$, which ensures that all the measured points are located in the original rock stress area.

According to the above measuring point layout principle, combined with the site construction records and surrounding rock exposed situation, after full communication with the site technical personnel, the location of each measuring point is determined. See Table 1 for the location of measuring points and description of drilling conditions.

2.2. Measurement Steps. According to the basic principle of the stress relief method of the hollow inclusion strain gauge, the specific measurement test steps are shown in Figure 2.

(1) A horizontal borehole with a diameter of $130 \mathrm{~mm}$ was drilled on the tunnel wall of the selected measuring point to a depth of more than 2.5 times of the tunnel span. The drilling hole is tilted up by 1-3 degrees so that cooling water can flow out and the drilling hole can be easily cleaned.

(2) The bottom of the hole is ground flat with a grinding bit, and a conical bit is used to make a bell, and then a concentric hole with a diameter of $42 \mathrm{~mm}$ is drilled from the bottom of the hole, with a depth of $35-40 \mathrm{~cm}$. The bell mouth plays an important role in ensuring the concentricity of the hole and making the hollow inclusion strain gauge enter the hole smoothly, so the quality of the bell mouth must be guaranteed. After drilling the small hole, rinse it with water, and send the wiping head soaked in alcohol into the small hole to scrub back and forth, so as to thoroughly remove oil and other dirt in the small hole.

(3) The adhesive (epoxy resin) and curing agent are mixed in proportion, mixed evenly, and injected into the cavity of the strain gauge, the plunger is fixed with the pin, and then the plunger is sent to the predetermined position in the small hole with the mounting rod with the orienter. After the conical head of the front part of the strain gauge touches the bottom of the small hole, the mounting rod is pushed hard to cut off the plug so that the plunger enters into the cavity. The cementing agent in the cavity flows into the annular gap between the strain gauge and the borehole wall through the central hole and the radial hole of the back part of the plunger. Sealing rings at both ends of the strain gauge will prevent the cement from flowing out of the gap. When the cement is cured, the strain gauge is tightly bonded with the hole.

(4) The stress relief test can be carried out after the cementing agent is solidified (generally about 20 hours). Before relieving the stress, the camera wire and cable are taken out from the core tube and drill 
TABLE 1: Surface location of each measuring point and parameters of the test hole for in situ stress.

\begin{tabular}{|c|c|c|c|c|c|c|c|}
\hline No. & Location & Mileage & $\begin{array}{l}\text { Hole } \\
\text { depth } \\
(\mathrm{m})\end{array}$ & $\begin{array}{l}\text { Borehole } \\
\text { inclination }\end{array}$ & $\begin{array}{c}\text { Buried } \\
\text { depth }(m)\end{array}$ & $\begin{array}{l}\text { Surrounding } \\
\text { rock grade }\end{array}$ & Surrounding rock properties \\
\hline $1 \#$ & Manmo Tunnel & DK413+ 505 & 19.3 & $3.5^{\circ}$ & 320 & IV & $\begin{array}{l}\text { Mudstone intercalated with } \\
\text { sandstone, shale, and } \\
\text { conglomerate }\end{array}$ \\
\hline $2 \#$ & $\begin{array}{l}\text { No. } 2 \text { inclined shaft of } \\
\text { the Mamushu Tunnel }\end{array}$ & $\mathrm{X} 2 \mathrm{DK} 0+009$ & 18.1 & $3.1^{\circ}$ & 450 & III & $\begin{array}{l}\text { Mudstone, shale intercalated } \\
\text { with sandstone }\end{array}$ \\
\hline $3 \#$ & $\begin{array}{c}\text { Exit of the Mamushu } \\
\text { Tunnel }\end{array}$ & $\mathrm{DK} 430+985$ & 20.5 & $3^{\circ}$ & 120 & IV & $\begin{array}{l}\text { Mudstone intercalated with } \\
\text { sandstone }\end{array}$ \\
\hline $4 \#$ & $\begin{array}{c}\text { Exit of the Mamushu } \\
\text { Tunnel }\end{array}$ & $\mathrm{DK} 430+560$ & 18.6 & $3.6^{\circ}$ & 220 & IV & $\begin{array}{c}\text { Shale intercalated with } \\
\text { mudstone, sandstone, slate, and } \\
\text { marl }\end{array}$ \\
\hline $5 \#$ & $\begin{array}{l}\text { No. } 3 \text { inclined shaft of } \\
\text { the Mamushu Tunnel }\end{array}$ & DK429+480 & 19.6 & $2.6^{\circ}$ & 540 & IV & $\begin{array}{l}\text { Quartz sandstone intercalated } \\
\text { with sandstone and mudstone }\end{array}$ \\
\hline
\end{tabular}

Note. Upward inclination of the borehole is positive.

pipe. Then, a thin-walled drill with a diameter of $130 \mathrm{~mm}$ is used to continue to deepen the large hole so that the rock around the strain gauge is gradually separated from the surrounding rock, so as to realize the stress relief of the casing core. During the stress relief process, the strain values measured by using the strain gauges in the strain gauge are automatically recorded by the bridge conversion device and the data acquisition device. According to the instruction, the strain data are recorded every 1 minute.

After the stress relief is completed, the strain data stored in the data collector are printed out by using the computer, and the stress relief curve is drawn, that is, the curve of the strain value of each strain gauge changing with the stress relief depth.

\subsection{Hollow Inclusion Strain Gauge with Complete Tempera-} ture Compensation. The hollow inclusion strain gauge with complete temperature compensation is based on the most widely used hollow inclusion strain gauge in the world. Figure 3 shows the distribution diagram of the strain flower position of the hollow inclusion strain gauge used this time. Its structure and working principle are basically the same as those of the CSIRO hollow inclusion strain gauge introduced earlier.

In Figure 3, a thermistor is embedded at point $\mathrm{D}$ between strain flowers A and C. The thermistor has been calibrated in the laboratory in advance, and the temperature change between $0^{\circ} \mathrm{C}$ and $40^{\circ} \mathrm{C}$ can be measured accurately with an error of $0.1^{\circ} \mathrm{C}$. At point E, two no-load wires which are the same as the resistance strain gauge wires are welded together, led out from the cable together with other strain gauge wires and thermistor wires, and connected into the measurement and recording system. In order to improve the reliability of measurement, each group of strain gauges is changed from 3 strain gauges of the CSIRO hollow inclusion strain gauge to 4 strain gauges.

From the head to the tail of the strain gauge, the clockwise sequence of strain flowers is A-B-C. The strain gauges parallel to the drilling direction are $0 \#$ strain gauges,

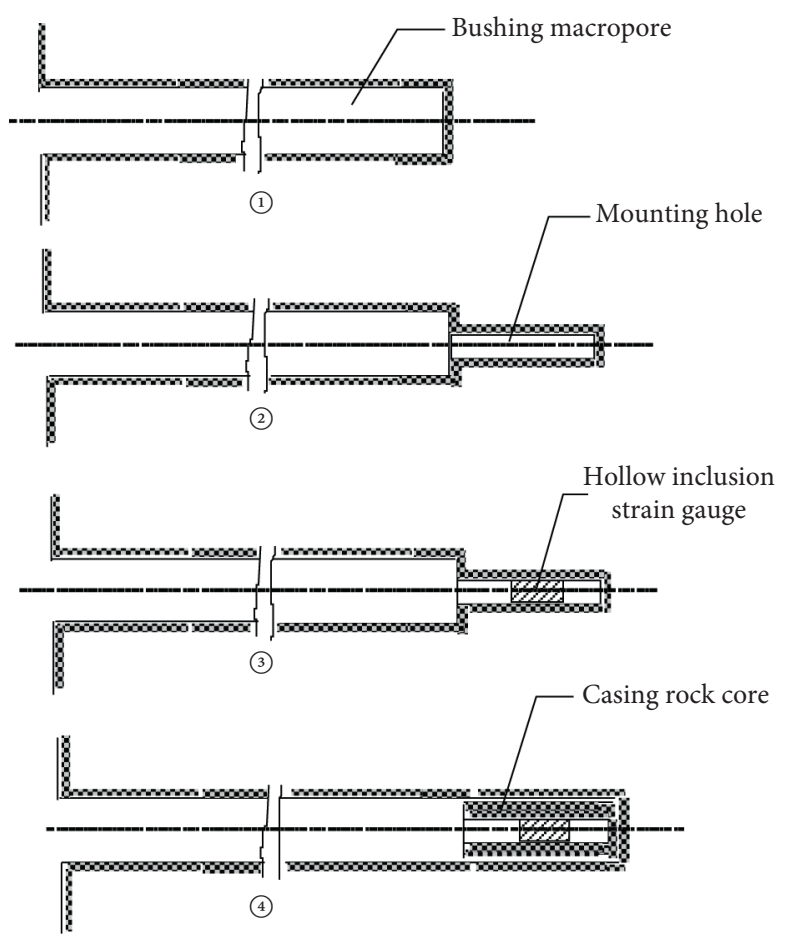

FIgURE 2: Schematic diagram of measurement steps of the stress relief method.

which are $45^{\circ}, 90^{\circ}$, and $135^{\circ}$ clockwise. Take a group of strain gauges as an example; 1 \# strain gauge is circumferential, and the strain gauge is marked as $\mathrm{A}_{90} ; 2 \#$ strain gauge is axial, and the strain gauge is marked as $\mathrm{A}_{0} ; 3 \#$ strain gauge and $4 \#$ strain gauge are, respectively, $\pm 45^{\circ}$ to the borehole axis, which are marked as $A_{45}$ and $A_{135}$. Similarly, 5\#-12\# strain gauges are recorded as $\mathrm{B}_{90}, \mathrm{~B}_{0}, \mathrm{~B}_{45}, \mathrm{~B}_{135}, \mathrm{C}_{90}, \mathrm{C}_{0}, \mathrm{C}_{45}$, and $\mathrm{C}_{135}$, respectively. Therefore, there are 12 strain gauges in the hollow inclusion strain gauge with complete temperature compensation, including 3 circumferential strain gauges $\left(\mathrm{A}_{90}, \mathrm{~B}_{90}\right.$, and $\left.\mathrm{C}_{90}\right)$ and axial $3\left(\mathrm{~A}_{0}, \mathrm{~B}_{0}\right.$, and $\left.\mathrm{C}_{0}\right)$; there are 3 branches $\left(\mathrm{A}_{45}, \mathrm{~B}_{45}\right.$, and $\left.\mathrm{C}_{45}\right)$ in the direction of $45^{\circ}$ to the axis; there are three branches $\left(\mathrm{A}_{135}, \mathrm{~B}_{135}\right.$, and $\left.\mathrm{C}_{135}\right)$ in the direction of $-45^{\circ}$ to the axis. 


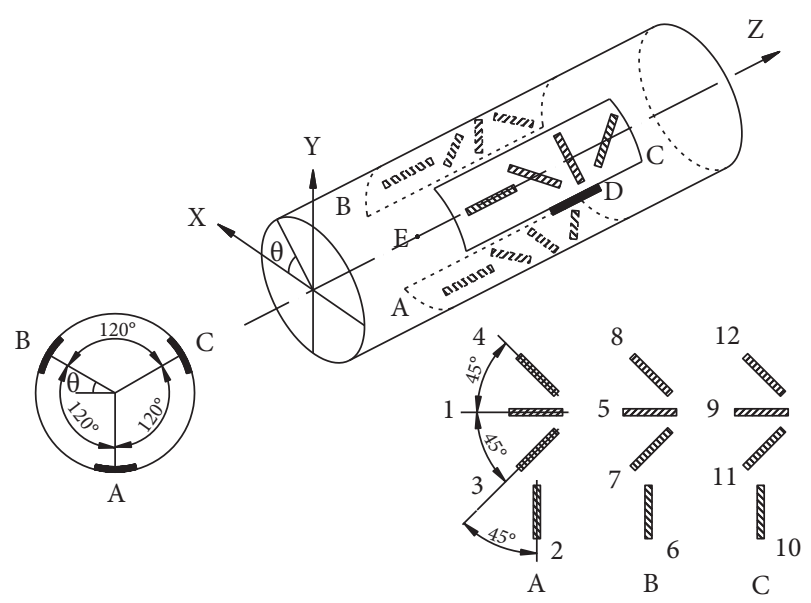

FIgURE 3: Structure diagram of the hollow inclusion strain gauge with complete temperature compensation.

In the process of installing the strain gauge, firstly, the adhesive is injected into the cavity of the strain gauge, the plunger is inserted into the tail of the cavity and fixed with the aluminum alloy wire bolt, and then it is sent into the small hole with the mounting rod. When the wedge head of the strain gauge is pushed to the bottom of the small hole, the force is applied to push the mounting rod, the bolt is cut off, the plunger is gradually pushed into the cavity, and the adhesive is extruded from the cavity and flows into the annular gap between the strain gauge and the small hole through the central hole and four side holes of the plunger, and the sealing rings at both ends of the strain gauge prevent the adhesive from flowing out of the gap. When the cement is cured, the strain gauge is tightly bonded with the hole.

2.4. Field Measurement. From October 2019 to January 2020, the in situ stress measurement group completed the testing work of 5 measuring points in the Manmushu Tunnel and Manmo Tunnel. Due to the poor data of the initial relief results of two measuring points, the in situ stress measurement research group carried out additional measurement in the original borehole, so the number of measured points is 7, which makes the final relief data more ideal and provides reliable guarantee for the later data processing and the formation of the final stress results.

Figure 4 shows the photos of the borehole and the core obtained. The borehole is straight and smooth, which is conducive to the installation of the strain gauge probe, so as to ensure the smooth and orderly development of the whole lifting process.

In the process of in situ stress test, the quality of drilling directly affects the final result of the in situ stress test. The in situ stress measurement group has taken a series of measures, such as prejob training, scientific selection of drilling tools, and on-site follow-up, to ensure that the quality of drilling meets the requirements of on-site measurement by the stress relief method. The core obtained after lifting can completely cover the hollow inclusion strain gauge. The core with hollow inclusion installed at each measuring point after lifting is shown in Figure 5.

\section{In Situ Stress Measurement Results of the Manmushu Tunnel and Manmo Tunnel}

3.1. Stress Relief Test Results. Figure 6 shows the in situ stress relief curves of each measuring point in this in situ stress measurement. It can be seen that the changes of strain and footage depth are basically synchronous in the process of core relief. Before the relief depth of the casing hole reaches the measured section (i.e., the section where the strain gauge is located), the strain value measured by each strain gauge is generally small, which is the result of stress transfer caused by the casing hole, equivalent to "excavation effect"; when the drill bit passes near the measuring section, the measured strain is the largest; when the casing depth exceeds a certain distance from the measured section, the curve tends to be stable, and the final stable value will be used as the original data for calculating the in situ stress.

According to the results recorded by the data collector, the stable strain values of each strain gauge of 9 measuring points are obtained, as shown in Table 2. There are 12 strain gauges at each measuring point, and strain values in 12 directions are measured. A90, A0, A45, A135, B90, B0, B45, $\mathrm{B} 135, \mathrm{C} 90, \mathrm{C} 0, \mathrm{C} 45$, and $\mathrm{C} 135$ represent 12 strain gauges, respectively. Among them, A, B, and $\mathrm{C}$ represent three groups of strain flowers, each group of strain flowers is composed of four strain gauges, and subscript numbers (90, 0,45 , and 135) indicate the angle between the strain gauge and the drilling axis.

3.2. Casing Rock Core Temperature Calibration Results. During the test, the casing core was placed in a constant box with adjustable temperature. The strain gauge wires are connected to the bridge conversion device, and the initial strain is adjusted to zero one by one. Then, the temperature is increased by $5^{\circ} \mathrm{C}$ every 4 hours, and the strain value measured by each strain gauge in each temperature section is recorded. The data acquisition and recording are still completed automatically by the data collector. Since the thermistor is still located in the strain gauge part of the strain gauge in the core, it is the most reliable and accurate way to measure the temperature value of the strain gauge part. At the same time, the temperature in the incubator is also monitored by using a platinum film digital thermometer with high sensitivity. It takes about 4 hours to homogenize the temperature in the core; that is, the temperature in the strain gauge is the same as that in the incubator. The temperature strain rate of each strain gauge can be obtained according to the strain data and temperature value measured by each strain gauge when the temperature rises, that is, the additional temperature strain value caused by every $1^{\circ} \mathrm{C}$ temperature rise in the strain gauge. The temperature change of the strain gauge can be obtained by converting the change of the thermistor in the hollow inclusion strain gauge during the stress relief process. By multiplying the temperature strain rate obtained from the temperature calibration test by 

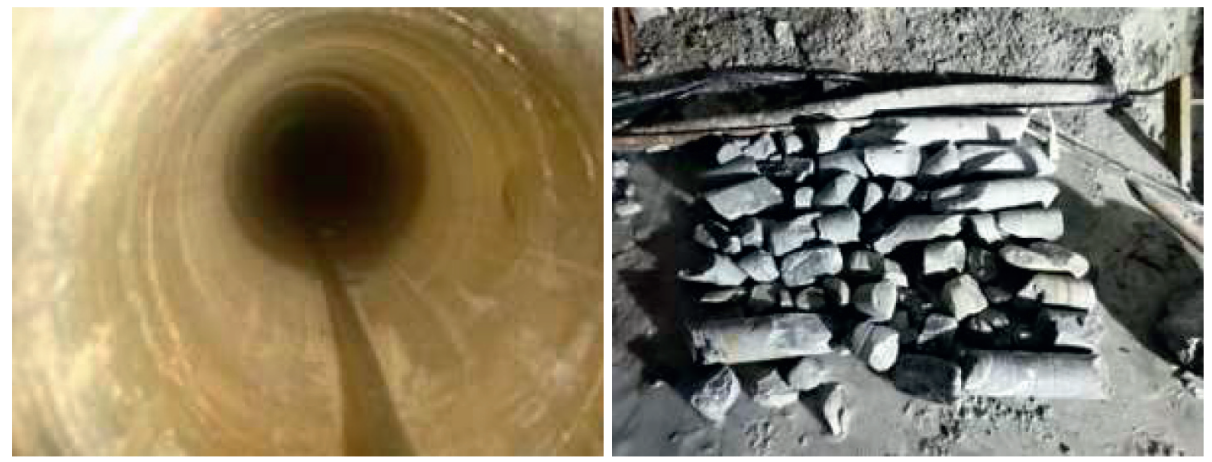

FIgURE 4: Site drilling and cores obtained.

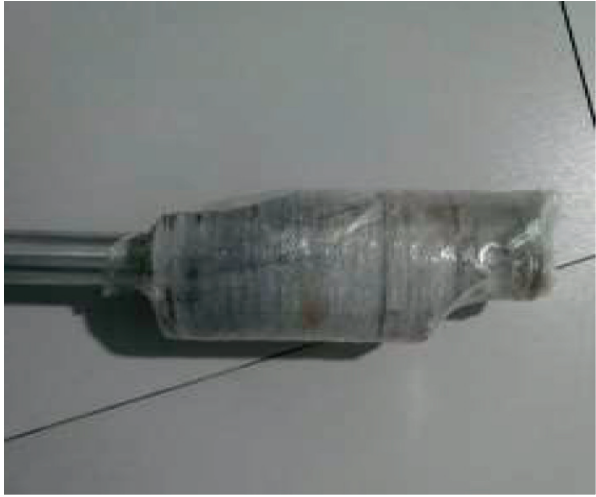

(a)

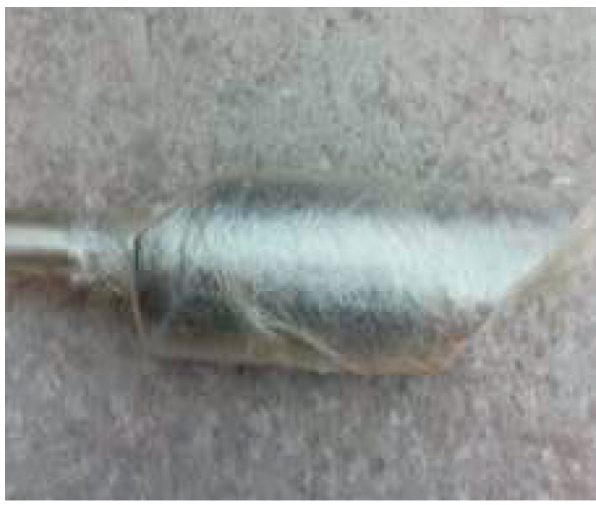

(c)

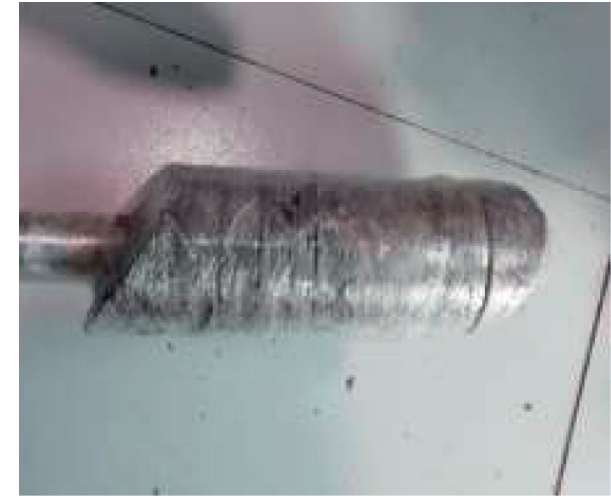

(b)

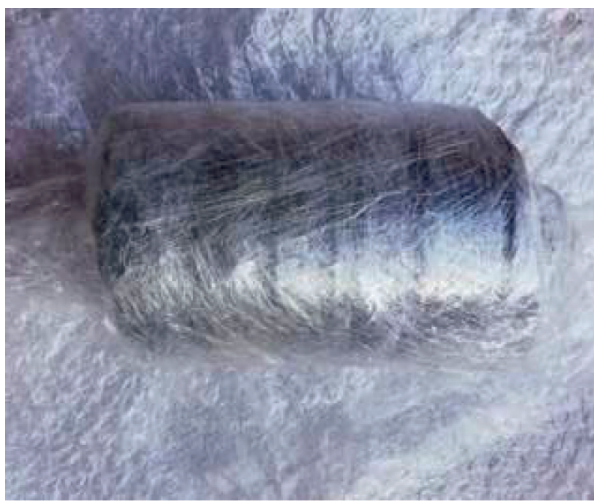

(d)

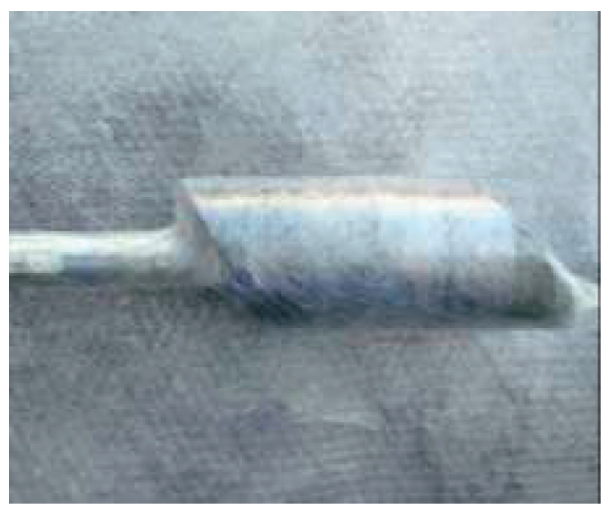

(e)

Figure 5: Core with hollow inclusion after release. (a) Measuring point 1. (b) Measuring point 2. (c) Measuring point 3. (d) Measuring point 4. (e) Measuring point 5 . 


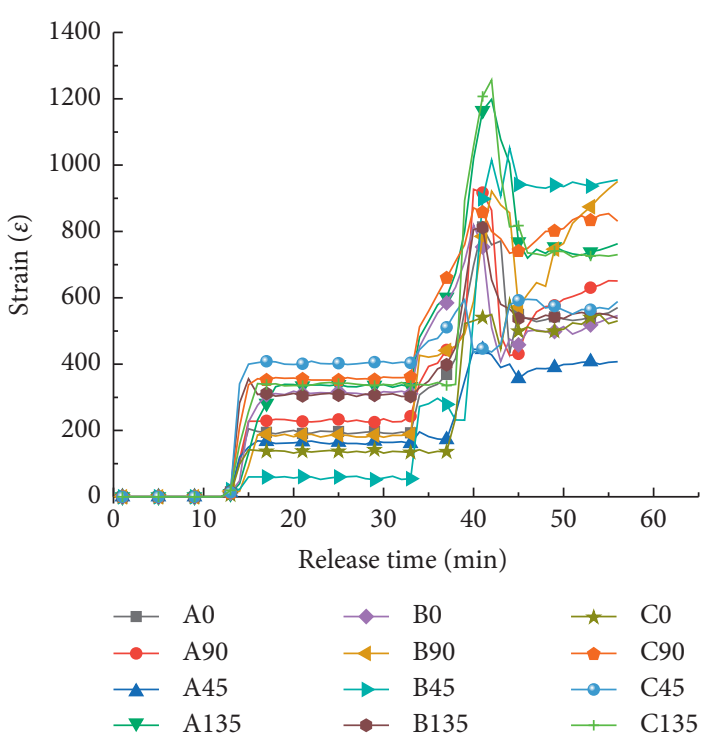

(a)

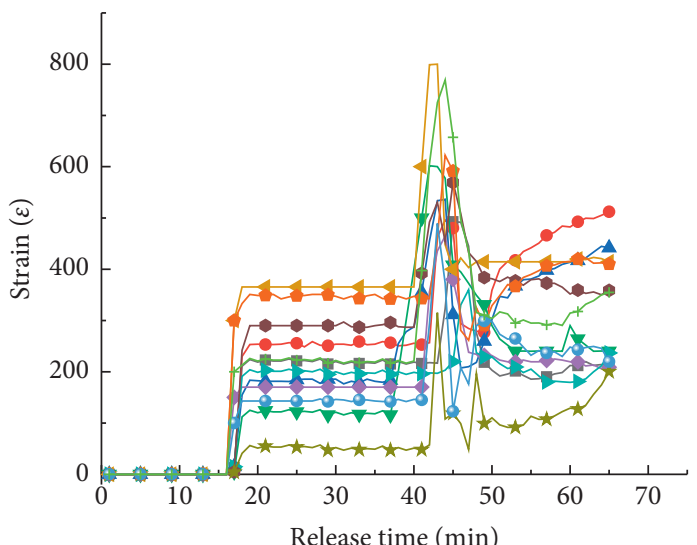

(c)

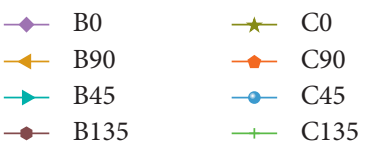

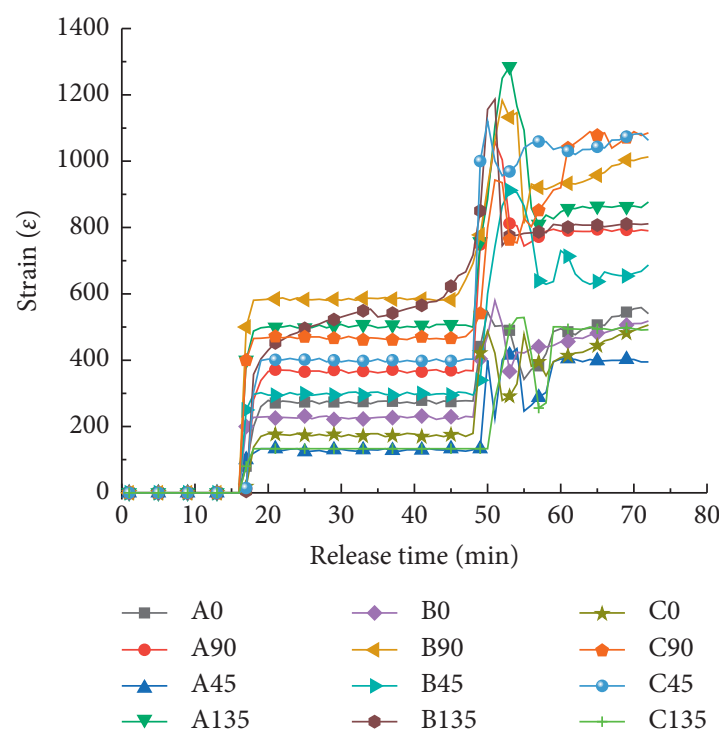

(b)

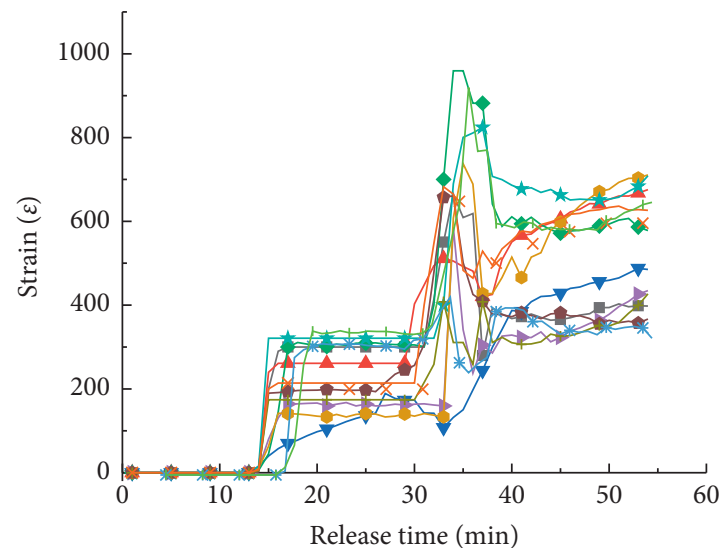

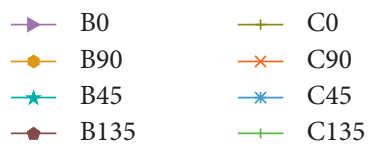

(d)

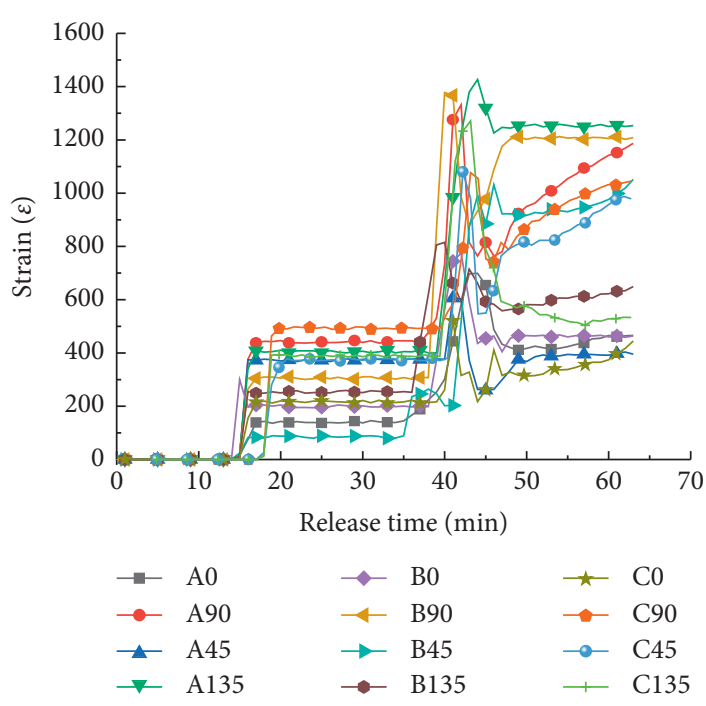

(e)

FIGURE 6: Stress relief curve of each measuring point. (a) Measuring point 1. (b) Measuring point 2. (c) Measuring point 3. (d) Measuring point 4. (e) Measuring point 5. 
TABLE 2: The final stable strain value measured by each strain gauge at each measuring point.

\begin{tabular}{|c|c|c|c|c|c|c|c|c|c|c|c|c|}
\hline \multirow{2}{*}{ No. } & \multicolumn{12}{|c|}{ Strain value $(\mu \varepsilon)$} \\
\hline & $\mathrm{A}_{90}$ & $\mathrm{~A}_{0}$ & $\mathrm{~A}_{45}$ & $\mathrm{~A}_{135}$ & $\mathrm{~B}_{90}$ & $\mathrm{~B}_{0}$ & $\mathrm{~B}_{45}$ & $\mathrm{~B}_{135}$ & $\mathrm{C}_{90}$ & $\mathrm{C}_{0}$ & $\mathrm{C}_{45}$ & $\mathrm{C}_{135}$ \\
\hline 1 & 651 & 570 & 408 & 763 & 951 & 547 & 956 & 538 & 831 & 530 & 589 & 731 \\
\hline 2 & 790 & 540 & 394 & 877 & 1013 & 518 & 686 & 811 & 1085 & 506 & 1062 & 492 \\
\hline 3 & 512 & 213 & 442 & 240 & 415 & 209 & 237 & 359 & 410 & 200 & 220 & 355 \\
\hline 4 & 677 & 398 & 485 & 577 & 712 & 434 & 708 & 368 & 626 & 426 & 342 & 680 \\
\hline 5 & 1187 & 465 & 396 & 1253 & 1208 & 465 & 1052 & 650 & 1046 & 445 & 980 & 534 \\
\hline
\end{tabular}

the temperature change value of the strain gauge during the stress relief process, the additional strain value of each strain gauge caused by the temperature change of the measuring point during the stress relief process can be obtained. By removing this part of the additional strain from the final stable strain measured in the process of stress relief, the true strain value caused by stress relief can be obtained. See Table 3 for additional temperature strain rate of the strain gauge in each direction at each measuring point.

It can be seen from Table 3 that when the temperature increases, the strain value of the strain gauge increases with the temperature, and the temperature strain rate is not the same at different temperatures. The temperature strain rate corresponding to the temperature range of the tunnel test must be used in the calculation.

The temperature change of each measuring point recorded in the process of stress relief is generally $1-2^{\circ} \mathrm{C}$. This temperature change value is multiplied by the temperature strain rate of each strain gauge of each measuring point shown in Table 2, and the additional temperature strain value of each strain gauge caused by the temperature change of the measuring point in the process of stress relief can reach $50-100 \mu \varepsilon$. It can be seen that temperature is an important factor for in situ stress measurement. It is of great significance to adopt correct methods to compensate or correct the influence of temperature to ensure the accuracy of in situ stress measurement results. After the stable strain value measured in the process of stress relief is corrected by the temperature effect, the strain value of the hollow inclusion strain gauge in each direction caused by stress relief is obtained, which is the strain value finally used to calculate the in situ stress (see Table 4).

\subsection{Core Confining Pressure Test}

3.3.1. Test Principle and Procedure. The equation for calculating in situ stress from the strain data measured by the hollow inclusion strain gauge during the stress relief process is the same as that of the hole wall strain gauge, but in the hollow inclusion strain gauge, the strain gauge is embedded in the cylinder wall of the strain gauge rather than pasted on the hole wall, and it is about $1.5 \mathrm{~mm}$ away from the hole wall, so the strain value measured by using the strain gauge is different from that measured by using the hole wall strain gauge. In order to correct this difference, Worotnicki and Walton added four correction coefficients (collectively referred to as coefficients) in equations (1)-(4), as shown in the following form:
TABLE 3: Additional temperature strain rate of the strain gauge in each direction at each measuring point.

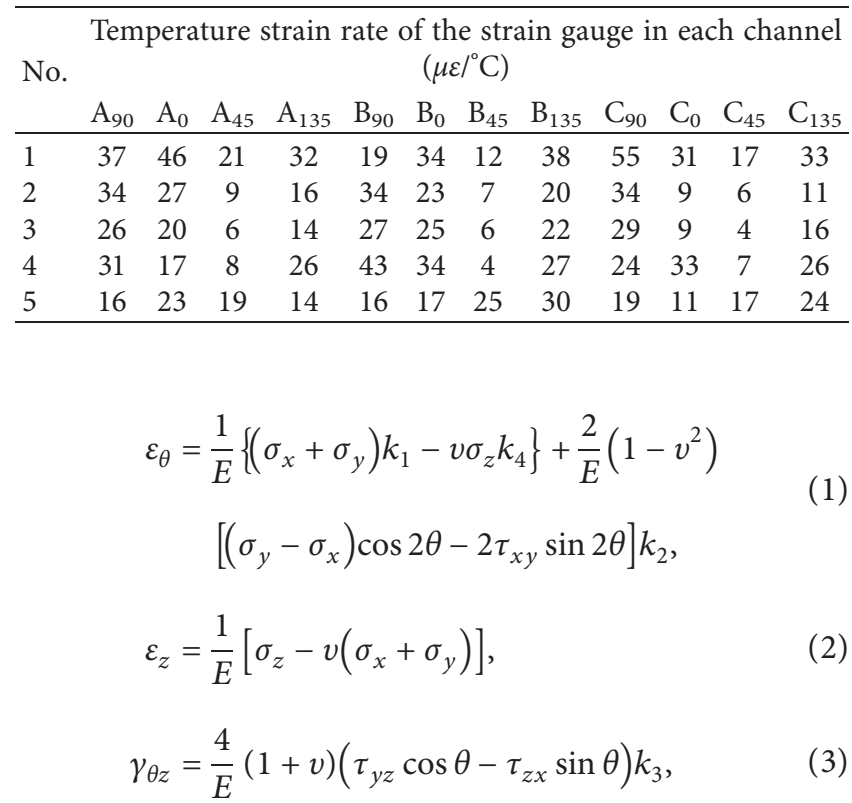

where $\varepsilon_{\theta}, \varepsilon_{z}$, and $\gamma_{\theta z}$ are the values of circumferential strain, axial strain, and shear strain measured, respectively. The coefficient $k$ is calculated as follows:

$$
\begin{aligned}
& k_{1}=d_{1}\left(1-v_{1} v_{2}\right)\left[1-2 v_{1}+\frac{R_{1}^{2}}{\rho^{2}}\right]+v_{1} v_{2}, \\
& k_{2}=\left(1-v_{1}\right) d_{2} \rho^{2}+d_{3}+v_{1} \frac{d_{4}}{\rho^{2}}+\frac{d_{5}}{\rho^{4}} \\
& k_{3}=d_{6}\left(1+\frac{R_{1}^{2}}{\rho^{2}}\right), \\
& k_{4}=\left(v_{2}-v_{1}\right) d_{1}\left(1-2 v_{1}+\frac{R_{1}^{2}}{\rho^{2}}\right) v_{2}+\frac{v_{1}}{v_{2}},
\end{aligned}
$$

where

$$
\begin{aligned}
& d_{1}=\frac{1}{1-2 v_{1}+m^{2}+n\left(1-m^{2}\right)}, \\
& d_{2}=\frac{12(1-n) m^{2}\left(1-m^{2}\right)}{R_{2}^{2} D},
\end{aligned}
$$


TABLE 4: Final strain values of each measuring point used to calculate in situ stress.

\begin{tabular}{|c|c|c|c|c|c|c|c|c|c|c|c|c|}
\hline \multirow{2}{*}{ No. } & \multicolumn{12}{|c|}{ Strain value $(\mu \varepsilon)$} \\
\hline & $\mathrm{A}_{90}$ & $\mathrm{~A}_{0}$ & $\mathrm{~A}_{45}$ & $\mathrm{~A}_{135}$ & $\mathrm{~B}_{90}$ & $\mathrm{~B}_{0}$ & $\mathrm{~B}_{45}$ & $\mathrm{~B}_{135}$ & $\mathrm{C}_{90}$ & $\mathrm{C}_{0}$ & $\mathrm{C}_{45}$ & $\mathrm{C}_{135}$ \\
\hline 1 & 595 & 501 & 376 & 715 & 922 & 496 & 938 & 481 & 748 & 483 & 563 & 681 \\
\hline 2 & 739 & 499 & 380 & 853 & 962 & 483 & 675 & 781 & 1034 & 492 & 1053 & 475 \\
\hline 3 & 473 & 183 & 433 & 219 & 374 & 171 & 228 & 326 & 366 & 186 & 214 & 331 \\
\hline 4 & 630 & 372 & 473 & 538 & 647 & 383 & 702 & 327 & 590 & 376 & 331 & 641 \\
\hline 5 & 1163 & 430 & 367 & 1232 & 1184 & 439 & 1014 & 605 & 1017 & 428 & 954 & 498 \\
\hline
\end{tabular}

$$
\begin{aligned}
& d_{3}=\frac{1}{D}\left[m^{4}\left(4 m^{2}-3\right)(1-n)+x_{1}+n\right], \\
& d_{4}=\frac{-4 R_{1}^{2}}{D}\left[m^{6}(1-n)+x_{1}+n\right], \\
& d_{5}=\frac{3 R_{1}^{4}}{D}\left[m^{4}(1-n)+x_{1}+n\right], \\
& d_{6}=\frac{1}{1+m^{2}+n\left(1-m^{2}\right)} .
\end{aligned}
$$

Among them,

$$
\begin{aligned}
n= & \frac{G_{1}}{G_{2}}, \\
m= & \frac{R_{1}}{R_{2}} \\
D= & \left(1+x_{2} n\right)\left[x_{1}+n+(1-n)\left(3 m^{2}-6 m^{4}+4 m^{6}\right)\right] \\
& +\left(x_{1}-x_{2} n\right) m^{2}\left[(1-n) m^{6}+\left(x_{1}+n\right)\right], \\
x_{1}= & 3-4 v_{1}, \\
x_{2}= & 3-4 v_{2},
\end{aligned}
$$

where $R_{1}$ is the inner radius of hollow inclusion, $R_{2}$ is the installation hole radius, $G_{1}, G_{2}$ are rigid moduli of hollow inclusion material and rock, respectively, $u_{1}, u_{2}$ are Poisson's ratio of hollow inclusion materials and rocks, respectively, and $\rho$ is the radial distance of the resistance strain gauge in the hollow inclusion.

It can be seen from equations (4)-(7) that $k$ is a variable related to elastic modulus and Poisson's ratio of rock and hollow inclusion material, geometry of hollow inclusion, and drilling radius, rather than a fixed number applicable to all cases. For each stress relief test, the stress of the measuring point must be calculated $k$ coefficient value.

The test was carried out on the confining pressure calibrator, which consists of an oil pump and a cylindrical oil cylinder (Figure 7). The experimental steps of confining pressure calibration are as follows:

(1) The casing core is placed in the cylindrical oil cylinder of the confining pressure calibrator, and the strain gauge is located in the middle of the cylinder; the strain gauge wires are connected to the bridge conversion device, and the initial strain readings of each channel are adjusted to zero one by one.

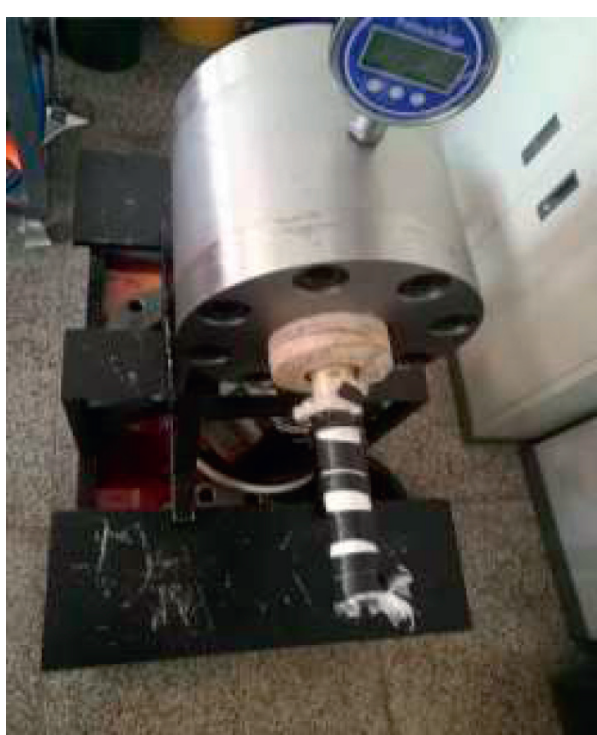

FIGURE 7: Schematic diagram of the confining pressure calibrator.

(2) The manual oil pump is used to pressurize the casing core, and the strain values of each strain gauge in the hollow inclusion strain gauge caused by the confining pressure are automatically collected and recorded by the data collector according to the instructions. A reading is recorded for every $2 \mathrm{MPa}$ increase of pressure until the pressure increases to $12-16 \mathrm{MPa}$. Then, the pressure is released, and the reading for every $2 \mathrm{MPa}$ is recorded.

(3) After complete pressure relief, the above pressure relief process is repeated. The pressure relief trend of this process is used to calculate the elastic modulus and Poisson's ratio.

If the rock is continuous, homogeneous, and isotropic and the working state of the strain gauge is normal and reliable, the strain value in the same angle direction with the drilling axis should be very close, and the circumferential strain is compressive strain, and the axial strain is tensile strain. The oblique strain is compressive strain, but the strain value is less than the circumferential strain.

3.3.2. Calculation of Rock Elastic Modulus, $k$-Coefficient, and Original Rock Stress. The elastic modulus and Poisson's ratio of the rock are generally determined by the confining pressure test of the casing core. If the strain gauge is directly attached to the wall of the small hole, the strain value 
measured by the confining pressure test can be solved by the thick wall cylinder equation of elasticity.

$$
\begin{aligned}
& E=\left(\frac{P_{0}}{\varepsilon_{\theta}}\right) \frac{R^{2}}{\left(R^{2}-r^{2}\right)}, \\
& v=\frac{\varepsilon_{\theta}}{\varepsilon_{z}},
\end{aligned}
$$

where $P_{0}$ is the confining pressure value, $\varepsilon_{\theta}, \varepsilon_{z}$ are the mean circumferential strain and mean axial strain caused by confining pressure, and $r, R$ are the inner and outer diameter of the casing core.

Since the strain gauge is not directly attached to the hole wall in the hollow inclusion strain gauge, the following correction equation should be adopted:

$$
E=k_{1} \frac{P_{0}}{\varepsilon_{\theta}} \frac{R^{2}}{\left(R^{2}-r^{2}\right)} .
$$

$k_{1}$ in equation (9) is $k_{1}$ in equation (4). It can be seen from equations (4) and (10) that the value of $E$ needs to be known when calculating $k$ coefficient, and the value of $k$ coefficient needs to be known when calculating $E$, so the iterative method must be used. When it is not possible to use the casing core for confining pressure test, the rock samples are taken from the measuring points for uniaxial or triaxial compression test to obtain the elastic modulus of the rock at the measuring points.

In addition, because of the nonlinear elasticity of rock mass, its elastic modulus is related to the stress level. In order to reduce the effect of nonlinearity, the elastic modulus used must be consistent with the calculated stress level. It will bring great error to calculate the low stress value by using the elastic modulus at the high stress level or the high stress value by using the elastic modulus at the low stress level. Generally, the secant modulus from 0 stress to the measured stress level is used to calculate the in situ stress. However, because the measured in situ stress is unknown, it must be solved by the iterative method. Therefore, it is necessary to adopt the double iteration method.
3.3.3. Calculation Results of Rock Elastic Modulus and Poisson's Ratio at Each Measuring Point. The elastic modulus and Poisson's ratio of the rock at each measuring point are obtained from the stress relief strain value calibrated by temperature and the confining pressure calibration test results. The calculation results are shown in Table 5 .

\subsection{Analysis of the 3D In Situ Stress State}

3.4.1. Construction of the In Situ Stress Calculation Program. According to the relationship between the strain of the hollow inclusion and the three-dimensional stress component (equations (1)-(3)) and the least square method of curve fitting, the calculation equation of the in situ stress component is derived, as shown in the following:

$$
\left.\begin{array}{l}
\sigma_{x}=\frac{B\left(c_{1}+c_{2}\right)-2 A c_{3}}{4\left(B X-A^{2}\right)}+\frac{c_{1}-c_{2}}{4 Y} \\
\sigma_{y}=\frac{B\left(c_{1}+c_{2}\right)-2 A c_{3}}{4\left(B X-A^{2}\right)}-\frac{c_{1}-c_{2}}{4 Y} \\
\sigma_{z}=\frac{-2 A\left(c_{1}+c_{2}\right)+4 X c_{3}}{4\left(B X-A^{2}\right)} \\
\tau_{x y}=\frac{\sqrt{3} E\left(2 \varepsilon_{5}+\varepsilon_{7}+\varepsilon_{8}-2 \varepsilon_{9}-\varepsilon_{11}-\varepsilon_{12}\right)}{36 k_{2}\left(1-\nu^{2}\right)} \\
\tau_{y z}=\frac{\sqrt{3} E\left(\varepsilon_{7}-\varepsilon_{8}-\varepsilon_{11}+\varepsilon_{12}\right)}{12 k_{2}(1+\nu)} \\
\tau_{z x}=\frac{E\left(2 \varepsilon_{3}-2 \varepsilon_{4}-\varepsilon_{7}+\varepsilon_{8}-\varepsilon_{11}+\varepsilon_{12}\right)}{12 k_{2}(1+\nu)}
\end{array}\right\},
$$

where

$$
\left.\begin{array}{l}
X=3 k_{1}^{2}+3 v^{2}+\frac{3}{2}\left(k_{1}-v\right) \\
Y=9 k_{2}^{2}\left(1-v^{2}\right)^{2} \\
A=-3 v\left(k_{1} k_{4}+1\right)+\frac{3}{2}\left(k_{1}-v\right)\left(1-v k_{4}\right) \\
B=3\left(v^{2} k_{4}^{2}+1\right)+\frac{3}{2}\left(1-v k_{4}\right)^{2}
\end{array}\right\},
$$

$$
\left.\begin{array}{l}
c_{1}-c_{2}=E k_{2}\left(1-\nu^{2}\right) \times\left(4 \varepsilon_{1}+2 \varepsilon_{3}+2 \varepsilon_{4}-2 \varepsilon_{5}-\varepsilon_{7}-\varepsilon_{8}-2 \varepsilon_{9}-\varepsilon_{11}-\varepsilon_{12}\right) \\
c_{1}+c_{2}=E\left[2 k_{1}\left(\varepsilon_{1}+\varepsilon_{5}+\varepsilon_{9}\right)-2 \nu\left(\varepsilon_{3}+\varepsilon_{6}+\varepsilon_{10}\right)+\left(k_{1}-\nu\right)\left(\varepsilon_{3}+\varepsilon_{4}+\varepsilon_{7}+\varepsilon_{8}+\varepsilon_{11}+\varepsilon_{12}\right)\right] \\
c_{3}=-E\left[\nu k_{4}\left(\varepsilon_{1}+\varepsilon_{5}+\varepsilon_{9}\right)-\left(\varepsilon_{2}+\varepsilon_{6}+\varepsilon_{10}\right)-\frac{1-\nu k_{4}}{2}\left(\varepsilon_{3}+\varepsilon_{4}+\varepsilon_{7}+\varepsilon_{8}+\varepsilon_{11}+\varepsilon_{12}\right)\right]
\end{array}\right\},
$$


Table 5: The values of elastic modulus $(E)$, Poisson's ratio $(v)$, and $k$ coefficient of each measuring point.

\begin{tabular}{lcccccc}
\hline Measuring point no. & $E(\mathrm{GPa})$ & $u$ & $k_{1}$ & $k_{2}$ & $k_{3}$ \\
\hline 1 & 21 & 0.25 & 1.034 & 1.043 & 1.025 & 0.936 \\
2 & 23 & 0.22 & 1.131 & 1.129 & 1.064 \\
3 & 22 & 0.20 & 1.122 & 1.109 & 0.905 \\
4 & 22 & 0.21 & 1.128 & 1.061 & 0.886 \\
5 & 24 & 0.25 & 1.135 & 1.124 & 1.030 & 0.978 \\
\hline
\end{tabular}

where $\sigma_{x}, \sigma_{y}, \sigma_{z}, \tau_{x y}, \tau_{y z}$, and $\tau_{z x}$ are the three-dimensional stress components at measuring points, $\varepsilon_{1}-\varepsilon_{12}$ are the measured strain values of 12 strain gauges, $E$ is the elastic modulus of the rock at the measuring point, $v$ is Poisson's ratio of the rock at the measuring point, and $k_{1}, k_{2}, k_{3}$, and $k_{4}$ are the correction coefficients given by Worotnicki and Walton.

Then, the calculation equations of the magnitude and direction of the principal stress are derived from the stress state equation and Shengjin equation. See equations (17)-(19).

$$
\begin{aligned}
\sigma_{1} & =\frac{I_{1}-2 \sqrt{J_{1}} \cos (T / 3)}{3} \\
\sigma_{2,3} & =\frac{I_{1}+\sqrt{J_{1}}(\cos (T / 3) \pm \sqrt{3} \sin (T / 3))}{3} \\
\theta & =90-\beta, \\
\varphi_{\sigma} & =\varphi_{z}-\varphi,
\end{aligned}
$$

where $\sigma_{1}, \sigma_{2}$, and $\sigma_{3}$ are three principal stresses at measuring points, $\quad T=\arcsin -2 J_{1} I_{1}-3 J_{2} / 2 \sqrt{J_{1}^{3}}, J_{1}=I_{1}^{2}-3 I_{2}, J_{2}=$ $9 I_{3}-I_{1} I_{2}, I_{1}=\sigma_{x}+\sigma_{y}+\sigma_{z}, I_{2}=\sigma_{x} \sigma_{y}+\sigma_{y} \sigma_{z}+\sigma_{x} \sigma_{z}-\tau_{x y}^{2}$ $-\tau_{x z}^{2}-\tau_{z y}^{2}, I_{3}=\left[\begin{array}{ccc}\sigma_{x} & \tau_{x y} & \tau_{x z} \\ \tau_{x y} & \sigma_{y} & \tau_{z y} \\ \tau_{x z} & \tau_{z y} & \sigma_{z}\end{array}\right], \theta$ is the inclination angle of principal stress. $\beta$ is the angle between the principal stress and $y$-axis, $\varphi_{\sigma}$ is the azimuth of principal stress, $\varphi_{z}$ is the azimuth of the $z$-axis, and $\varphi$ is the included angle formed by the positive direction of the $z$-axis rotating counterclockwise to the positive direction of the principal stress projection. The calculation formula is related to the quadrant of the principal stress, as shown in Table 6.

3.4.2. Calculation Results of Principal Stress at Each Measuring Point. According to the above model, the main stress calculation results of each measuring point are shown in Table 7.

3.5. Distribution Law and Model of Ground Stress in the Tunnel. According to the in situ stress test data of five measuring points shown in Table 6 , it can be found that the stress field distribution of the Manmushu Tunnel and Manmo Tunnel has the following rules:
(1) Each measuring point has two principal stresses close to the horizontal direction, and the maximum angle between them and the horizontal plane is not more than $20^{\circ}$; another principal stress is close to the vertical direction, and its angle with the vertical direction is not more than $20^{\circ}$.

(2) The maximum horizontal principal stress directions of the five measuring points are all located in the NW direction, which is basically consistent with the maximum principal stress direction of the regional tectonic stress field. The ratio of the maximum horizontal principal stress $\left(\sigma_{h \cdot \max }\right)$ to the vertical principal stress $\left(\sigma_{v}\right)$ is shown in Table 7 . Four of the five measuring points are more than 1.5 times, the maximum point is 1.81 times, the minimum point is 1.46 times, and the average is 1.60 times. It can be seen that the stress field of the Manmushu Tunnel and Manmo Tunnel is dominated by horizontal tectonic stress.

(3) The ratio of the maximum horizontal principal stress $\left(\sigma_{h \text { max }}\right)$ to the minimum horizontal principal stress $\left(\sigma_{h \text {.min }}\right)$ of the five measuring points is shown in Tables 8 and 9. The average value of the ratio of the maximum horizontal principal stress $\left(\sigma_{h . \max }\right)$ to the minimum horizontal principal stress $\left(\sigma_{h . m i n}\right)$ is 1.75 , and the maximum value is 1.92. According to the Mohr-Coulomb strength theory, the difference between the two principal stresses is shear stress, and the failure of rock mass is usually caused by shear failure. There is a large shear stress in the horizontal plane, which must be paid enough attention.

(4) The maximum horizontal principal stress $\left(\sigma_{h \cdot \max }\right)$, the minimum horizontal principal stress $\left(\sigma_{h \text {.min }}\right)$, and the vertical principal stress $\left(\sigma_{v}\right)$ all increase with the increase of buried depth, and the relationship is approximately linear. In order to better analyze the variation law of the in situ stress field with buried depth, the linear regression method is used to make regression analysis on the stress values of each measured point, and the regression equations and curves of the maximum horizontal principal stress, minimum horizontal principal stress, and vertical principal stress with buried depth are obtained. The regression equation is the tunnel stress field model. 
TABLE 6: The calculation equation of $\varphi$.

\begin{tabular}{|c|c|c|c|c|c|c|c|c|}
\hline Quadrant of principal stress & $\mathrm{I}$ & II & III & IV & $\mathrm{V}$ & VI & VII & VIII \\
\hline $\begin{array}{l}\text { Coordinate axis } \\
(l, m, n)\end{array}$ & $\begin{array}{l}(+,+,+) \\
(+,+,+)\end{array}$ & $\begin{array}{l}(-,+,+) \\
(-,+,+)\end{array}$ & $\begin{array}{l}(-,-,+) \\
(-,-,+)\end{array}$ & $\begin{array}{l}(+,-,+) \\
(+,-,+)\end{array}$ & $\begin{array}{l}(+,+,-) \\
(+,+,-)\end{array}$ & $\begin{array}{l}(-,+,-) \\
(-,+,-)\end{array}$ & $\begin{array}{l}(-,-,-) \\
(-,-,-)\end{array}$ & $\begin{array}{l}(+,-,-) \\
(+,-,-)\end{array}$ \\
\hline$\varphi$ & \multicolumn{4}{|c|}{$\arctan l / n$} & \multicolumn{4}{|c|}{$\pi+\arctan l / n$} \\
\hline
\end{tabular}

TABLE 7: Calculation results of principal stress at each measuring point.

\begin{tabular}{|c|c|c|c|c|c|c|c|c|c|c|}
\hline \multirow[b]{2}{*}{ No. } & \multirow{2}{*}{$\begin{array}{l}\text { Buried depth } \\
\text { (m) }\end{array}$} & \multicolumn{3}{|c|}{ Maximum principal stress $\sigma_{1}$} & \multicolumn{3}{|c|}{ Intermediate principal stress $\sigma_{2}$} & \multicolumn{3}{|c|}{ Minimum principal stress $\sigma_{3}$} \\
\hline & & $\begin{array}{l}\text { Value } \\
(\mathrm{MPa})\end{array}$ & Direction $\left({ }^{\circ}\right)$ & Angle $\left({ }^{\circ}\right)$ & $\begin{array}{l}\text { Value } \\
\text { (MPa) }\end{array}$ & Direction $\left(^{\circ}\right)$ & Angle $\left(^{\circ}\right)$ & $\begin{array}{l}\text { Value } \\
(\mathrm{MPa})\end{array}$ & Direction $\left(^{\circ}\right)$ & Angle $\left({ }^{\circ}\right)$ \\
\hline 1 & 320 & 15.77 & 325 & -16 & 9.90 & 348 & 73 & 8.20 & 237 & 6 \\
\hline 2 & 450 & 17.23 & 334 & 14 & 11.12 & 291 & 71 & 9.09 & 241 & 13 \\
\hline 3 & 120 & 6.44 & 344 & 7 & 4.32 & 73 & -10 & 4.11 & 287 & -77 \\
\hline 4 & 220 & 12.02 & 309 & 19 & 7.13 & 41 & 6 & 6.44 & 328 & -70 \\
\hline 5 & 540 & 19.74 & 347 & -9 & 13.48 & 298 & 76 & 11.22 & 255 & -10 \\
\hline
\end{tabular}

TABLe 8: Ratio of the maximum horizontal principal stress to vertical principal stress.

\begin{tabular}{lcccccc}
\hline No. & 1 & 2 & 3 & 4 & 5 & Average value \\
\hline$\sigma_{h . \max } / \sigma_{v}$ & 1.59 & 1.55 & 1.57 & 1.81 & 1.46 & 1.60 \\
\hline
\end{tabular}

TABLE 9: Ratio of the maximum horizontal principal stress to minimum horizontal principal stress.

\begin{tabular}{lcccccc}
\hline No. & 1 & 2 & 3 & 4 & 5 & Average value \\
\hline$\sigma_{h . \max } / \sigma_{v}$ & 1.92 & 1.90 & 1.49 & 1.69 & 1.76 & 1.75 \\
\hline
\end{tabular}

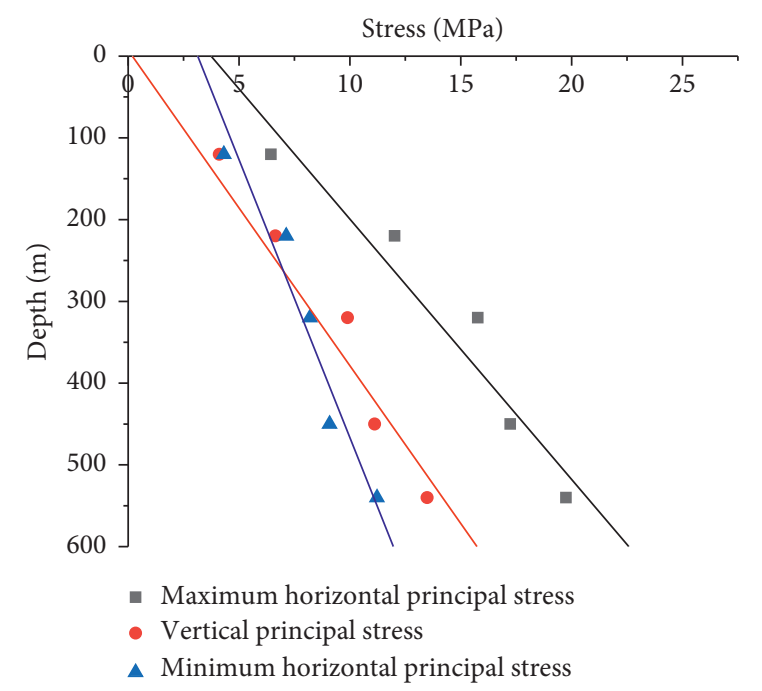

FIgURE 8: Regression curve of $\sigma_{\text {h.max }}, \sigma_{\text {h.min }}$, and $\sigma_{v}$ values with buried depth.

Regression equation (in situ stress field model):

$$
\begin{aligned}
\sigma h, \max & =0.0314 H+3.74, \\
\sigma h, \min & =0.0147 H+3.14, \\
\sigma v & =0.0259 H+0.19,
\end{aligned}
$$

where $\sigma_{h, \max }, \sigma_{h, \min }$, and $\sigma_{v}$ are the maximum horizontal principal stress, the minimum horizontal principal stress, and the vertical principal stress, respectively, and the unit is $\mathrm{MPa}$, and $H$ is the buried depth, and the unit is $\mathrm{m}$.

The regression curve is shown in Figure 8.

\section{Conclusions}

From October 2019 to January 2020, the research group of in situ stress measurement carried out tests at five measuring points in the Manmushu Tunnel and Manmo Tunnel in Southwest China. The measured results show the following:

(1) The maximum horizontal principal stress $\sigma_{h \text { max }}$ ranges from $6.44 \mathrm{MPa}$ to $19.74 \mathrm{MPa}$; the vertical principal stress $\sigma_{v}$ ranges from $4.11 \mathrm{MPa}$ to 13.48 $\mathrm{MPa}$; and the minimum horizontal principal stress ranges from $4.32 \mathrm{MPa}$ to $11.22 \mathrm{MPa}$.

(2) The maximum horizontal principal stress directions of the five measuring points are all located in the NW direction, which is basically consistent with the maximum principal stress direction of the regional tectonic stress field. The maximum horizontal principal stress $\left(\sigma_{h \cdot \max }\right)$, the minimum horizontal principal stress $\left(\sigma_{h \text { min }}\right)$, and the vertical principal stress $\left(\sigma_{v}\right)$ all increase with the increase of buried depth, and the relationship is approximately linear.

(3) It is suggested that, in the actual construction process, the construction method and construction parameters should be optimized scientifically and reasonably to reduce the disturbance of blasting on the tunnel surrounding rock. After tunnel excavation, support measures should be taken quickly, timely, and scientifically to reduce and control the deformation of the surrounding rock.

\section{Data Availability}

The data used to support the findings of this study are included within the article. 


\section{Conflicts of Interest}

The authors declare that there are no conflicts of interest regarding the publication of this paper.

\section{Acknowledgments}

The authors thank the Scientific Research Fund of China Academy of Railway Sciences Group Co., Ltd., for the support (no. 2020YJ089).

\section{References}

[1] Z. H. Xu, "Present situation and Prospect of in-situ stress research," Advances in Earth Science, vol. 5, no. 5, pp. 27-34, 1990.

[2] B. C. Haimson, Hydraulic Fracturing in Porus and Nonporus Rock and its Potential for Determining In-Situ Stresses at Great Depth, University of Minnesota, Minnesota, 1968.

[3] C. Fairhurst, "Measurement of in situ rock stresses with particular references to hydraulic fracturing," Rock Mechanics and Engineering Geology, vol. 2, pp. 129-147, 1964.

[4] F. Guo, N. R. Morgenstern, and J. D. Scott, "Interpretation of hydraulic fracturing pressure: a comparison of eight methods used to identify shut-in pressure," International Journal of Rock Mechanics and Mining Science \& Geomechanics Abstracts, vol. 30, no. 6, pp. 627-631, 1993.

[5] M. C. He, "Present situation and Prospect of rock mechanics in deep mining engineering," in Proceedings of the 8th $\mathrm{Na}$ tional Conference on Rock Mechanics and Engineering, pp. 88-96, Science Press, Chengdu, Beijing, August 2004.

[6] J. S. Li, H. Peng, X. M. Ma, Z. R. Shi, J. W. Li, and S. X. Yang, "Three-dimensional finite element numerical simulation of geo-stress in Da-Li Railway tunnel of Yunnan," Chinese Journal of Geotechnical Engineering, vol. 28, no. 6, pp. 800803, 2006.

[7] B. C. Haimson, C. F. Lee, and J. H. S. Huang, "High horizontal stresses at Niagara Falls their measurement and the design of anew hydroelectric plant," in Proceedings of the International Symposium on Rock Stress and Rock Stress Measurement, ISRM, Stockholm, Sweden, August 1986.

[8] G. X. Chen, Mechanism Research of the Maximum Horizontal Stress on Rockburst and its Application, China University of Mining and Technology, China, 2009.

[9] M. L. Zoback and M. Zoback, "State of stress in the conterminous United States," Journal of Geophysical Research: Solid Earth, vol. 85, no. B11, pp. 6113-6156, 1980.

[10] M. L. Zoback, "First and second order patterns of stress in the lithosphere: the world stress map project," Journal of Geophysical Research Solid Earth, vol. 97, no. 8, pp. 11703-11728, 1992.

[11] R. Govers, M. J. R. Wortel, S. A. P. L. Cloetingh, and C. A. Stein, "Stress magnitude estimates from earthquakes in oceanic plate interiors," Journal of Geophysical Research, vol. 97, no. B8, pp. 11749-11759, 1992.

[12] Z. Xu, S. Wang, Y. Huang, and A. Gao, "Tectonic stress field of China inferred from a large number of small earthquakes," Journal of Geophysical Research, vol. 97, no. B8, pp. 1186711877, 1992.

[13] V. S. Mount and J. Suppe, "Present-day stress orientations adjacent to active strike-slip faults: California and Sumatra," Journal of Geophysical Research, vol. 97, no. B8, pp. 1199512013, 1992.
[14] F. H. Cornet and D. Burlet, "Stress field determinations in France by hydraulic tests in boreholes," Journal of Geophysical Research, vol. 97, no. B8, pp. 11829-11849, 1992.

[15] E. R. Leeman, "The determination of the complete state of stress in rock in a single borehole-laboratory and underground measurements," International Journal of Rock Mechanics and Mining Science \& Geomechanics Abstracts, vol. 5, no. 1, pp. 31-38, 1968.

[16] M. Rocha, A. Silverio, J. O. Pedro, and J. S. Delgado, “A new development of the LNEC stress tensor gauge," Proceedings Of the 3rd ISRM Congress, pp. 464-467, ISRM, Denver, Colorado, 1974.

[17] G. Worotnicki and R. J. Walton, “Triaxial 'Hollow Inclusion' gauges for the determination of rock stress in situ," in Proceedings of ISRM Symposium on Investigation of Stress in Rock and Advances in Shear Measurement, pp. 1-8, Institution of Engineers, Australia, Sydney, N.S.W, Jan 1976.

[18] M. E. Duncan Fama and M. J. Pender, "Analysis of the hollow inclusion technique for measuring in Situ rock stress," International Journal of Rock Mechanics and Mining Science \& Geomechanics Abstracts, vol. 17, no. 3, pp. 137-146, 1980.

[19] M. R. Shen and J. F. Chen, Rock Mass Mechanics, Tongji University Press, China, 2nd Edition, 2015.

[20] S. M. Zhou, Some Rock Mechanics Problems of Complex Rock Mass, China Water Resources and Hydropower Press, China, 1998.

[21] Institute of geology, "Chinese Academy of Sciences, Engineering Geomechanics of Rock Mass, Vol. 8, " Science Press, Beijing, 1987.

[22] S. R. Su, Effect of Fractures on Rock Stresses and its Significance in Geological Engineering, Chengdu University of Technology, China, 2002.

[23] X. H. Chen, Study on the Occurrence Conditions of Tectonic Stress Type of Rock Burst, Liaoning Technical University, China, 2004.

[24] F. Q. Li and L. J. Wang, "In-site stress measurement in North China," Acta Geophysica Sinica, vol. 22, no. 1, pp. 1-8, 1979.

[25] F. Yin, "Application of in-situ stress measurement by acoustic emission in Xiaolangdi and other dam sites of the Yellow River," Renmin Huanghe, vol. 6, pp. 47-50, 1990.

[26] M. F. Cai, "Study of temperature compensation methods in Rock Stress measurements," Journal of Rock Mechanics and Engineering, vol. 10, no. 3, pp. 227-235, 1991.

[27] M. F. Cai, S. C. Xiong, L. Qiao, B. Yu, and G. Y. Kong, “A research technique for determining in-situ stress field with 3D FEM analysis," China Mining, vol. 6, no. 1, pp. 42-45, 1997.

[28] M. F. Cai and S. H. Wang, "Relationship between ground stress behaviour and properties of surrounding rock," China Mining, vol. 6, no. 6, pp. 38-42, 1997.

[29] F. Q. Li and Y. N. Qi, "Variation of crustal stress with depth in China," Chinese Journal of Rock Mechanics and Engineering, vol. 7, no. 4, pp. 301-309, 1988.

[30] X. Y. Ma, Summary of Lithospheric Dynamics in China, Geological Press, no. 2, pp. 113-125, China, 1987.

[31] K. M. Larson, R. Bürgmann, R. Bilham, and J. T. Freymueller, "Kinematics of the India-Eurasia collision zone from GPS measurements," Journal of Geophysical Research: Solid Earth, vol. 104, no. B1, pp. 1077-1093, 1999.

[32] T. Y. Fan, C. X. Long, Z. Y. Yang et al., "Comprehensive modeling on the present crustal stress of China mainland with the viscoelastic spherical shell," Chinese Journal of Geophysics, vol. 55, no. 4, pp. 1249-1260, 2012.

[33] Y. X. Li, X. K. Hu, C. K. Zhao, M. Wang, L. Q. Guo, and J. S. Xu, "Establishment of the GPS monitoring network in 
North China, the relation of horizontal crustal movement to stress field and seismicity," Earthquake Research in China, vol. 6, no. 2, pp. 116-125, 1998.

[34] S. H. Zheng, "Size relationship between focal tensor and focal parameters in Xizang plateau and its surroundings," Acta Seismologica Sinica, vol. 14, no. 4, pp. 423-434, 1992.

[35] J. F. Chai, "Research on multijoint rock failure mechanism based on moment tensor theory," Mathematical Problems in Engineering, vol. 2020, Article ID 6816934, 17 pages, 2020.

[36] W. B. Ma, J. F. Chai, Z. F. Li et al., "Research on vibration Law of railway tunnel substructure under different axle loads and health conditions," Shock and Vibration, vol. 2021, Article ID 9954098, 14 pages, 2021.

[37] Z. L. Han, W. B. Ma, J. F. Chai et al., "A treatment technology for optimizing the stress state of railway tunnel bottom structure," Shock and Vibration, vol. 2021, Article ID 9191232, 13 pages, 2021.

[38] W. B. Ma, J. F. Chai, Z. L. Han et al., "Research on design parameters and fatigue life of tunnel bottom structure of single-track ballasted heavy-haul railway tunnel with 40-ton axle load," Mathematical Problems in Engineering, vol. 2020, Article ID 3181480, 9 pages, 2020.

[39] J. Cheng, "Residential land leasing and price under public land ownership," Journal of Urban Planning and Development, vol. 147, no. 2, Article ID 05021009, 2021.

[40] J. Cheng, "Analysis of commercial land leasing of the district governments of Beijing in China," Land Use Policy, vol. 100, p. 2021, 104881.

[41] J. Cheng, "Analyzing the factors influencing the choice of the government on leasing different types of land uses: evidence from Shanghai of China," Land Use Policy, vol. 90, Article ID 104303, 2020.

[42] J. Cheng, "Data analysis of the factors influencing the industrial land leasing in Shanghai based on mathematical models," Mathematical Problems in Engineering, vol. 2020, Article ID 9346863, 11 pages, 2020.

[43] J. Cheng, "Mathematical models and data analysis of residential land leasing behavior of district governments of Beijing in China," Mathematics, vol. 9, no. 18, p. 2314, 2021.

[44] G. D. Zheng and Y. M. Cheng, "The improved element-free Galerkin method for diffusional drug release problems," International Journal of Applied Mechanics, vol. 12, no. 8, p. 2050096, 2020.

[45] Q. Wu, P. Peng, and Y. Cheng, "The interpolating elementfree Galerkin method for elastic large deformation problems," Science China Technological Sciences, vol. 64, no. 2, pp. 364374, 2021.

[46] H. Cheng, M. Peng, Y. Cheng, and Z. Meng, "The hybrid complex variable element-free Galerkin method for 3D elasticity problems," Engineering Structures, vol. 219, p. $110835,2020$.

[47] Y. Zhou, S. Feng, and J. Li, "Study on the failure mechanism of rock mass around a mined-out area above a highway tunnel s," Tunnelling and Underground Space Technology, vol. 118, p. 104182, 2021. 